\title{
Circadian blood pressure rhythm as a possible key target of SGLT2 inhibitors used for the treatment of Type 2 diabetes
}

\author{
Kouichi Tamura, Hiromichi Wakui, Kengo Azushima, Kazushi Uneda and Satoshi Umemura
}

Hypertension Research (2016) 39, 396-398; doi:10.1038/hr.2016.1; published online 28 January 2016

\begin{abstract}
$\mathrm{A}_{\mathrm{t}+x_{1}}$ ccumulating evidence has demonstrated that the prevalence of Type 2 diabetes mellitus (T2DM) is rapidly increasing and that renal and cardiovascular complications often provoke serious conditions in diabetic patients. ${ }^{1}$ Particularly, cardiovascular complications are the primary cause of death in diabetic patients with nephropathy. Major risk factors for cardiovascular disease (CVD) in patients with T2DM include hypertension, dyslipidemia, albuminuria (proteinuria) and decreased glomerular filtration rate (GFR). ${ }^{2-4}$

In treating $\mathrm{T} 2 \mathrm{DM}$, it is important to appropriately manage glucose and lipid metabolism, body weight and blood pressure (BP) and to suppress the development and progression of diabetic complications to restore the quality of life to a level comparable with healthy subjects. First-line therapy for T2DM includes diet modifications and exercise therapy, and if these measures are insufficient anti-diabetic medications are prescribed. Pharmacotherapy for T2DM consists of oral and injectable treatments. It is increasingly being reported that therapeutic intervention in the early stages of disease progression is important for the effective management of T2DM and diabetic nephropathy; thus, the specific diagnosis of albuminuria is a key component of this approach. Therefore, the Joint Committee on Diabetic Nephropathy of the Japan Diabetes Society and the Japanese Society of Nephrology has recently revised its Classification of Diabetic Nephropathy (Classification of Diabetic Nephropathy
\end{abstract}

K Tamura, H Wakui, K Azushima, K Uneda and $S$ Umemura are at Department of Medical Science and Cardiorenal Medicine, Yokohama City University Graduate School of Medicine, Yokohama, Japan E-mail: tamukou@med.yokohama-cu.ac.jp
2014), ${ }^{5}$ and the clinical significance of albuminuria in the management of T2DM has been highlighted in this new version. In one example of the significance of albuminuria to cardiovascular risk, a subanalysis of the Reduction of Endpoints in NIDDM with the Angiotensin II Antagonist Losartan (RENAAL) study and Irbesartan Diabetic Nephropathy Trial (IDNT), which included diabetic patients with overt albuminuria, demonstrated that the reduction of CVD risk was dependent not only on the achievement of adequate BP control but also on the sufficient decrease in albuminuria, independent of the achieved BP levels. ${ }^{6}$

Therefore, therapeutic intervention to effectively improve albuminuria is essential for reducing CVD risk in patients with T2DM, regardless of the stage of diabetic nephropathy. To that end, appropriate glycemic control, in addition to $\mathrm{BP}$ reduction, is critical for reducing albuminuria in patients with diabetic nephropathy. Achieving the target HbAlc of $<7.0 \%$ (National Glycohemoglobin Standardization Program (NGSP)) for glycemic control in T2DM patients with microalbuminuria is recommended in the Evidence-based Clinical Practice Guidelines for Chronic Kidney Disease (CKD) by the Japanese Society of Nephrology 2013.7 In a recent post hoc subanalysis of the ADVANCE trial, an intensive glucose-lowering regimen (with a target $\mathrm{HbAlC}$ of $<6.5 \%$ ) reduced the risk of end-stage renal disease and led to improvements in albuminuria. ${ }^{8}$ In addition, a previous meta-analysis of randomized controlled trials demonstrated that intensive glucose-lowering treatment was associated with a significant reduction in the risk of microalbuminuria in patients with T2DM. ${ }^{9}$
Currently, managing T2DM in patients with CKD represents a clinical challenge because of limited treatment options, as most oral anti-hyperglycemic agents exhibit decreased efficacy and/or delayed clearance and more adverse events in T2DM patients with a GFR of $<60 \mathrm{ml}$ per min per $1.73 \mathrm{~m}^{2} .{ }^{10}$ Nevertheless, several previous studies have demonstrated that intensified multi-factorial intervention with tight glucose regulation and renin-angiotensin system blockers, aspirin and lipid-lowering agents reduced the risk of CVD and death among T2DM patients with microalbuminuria. ${ }^{11}$ Although several therapies, such as mineralocorticoid receptor antagonists, are potential options for reducing albuminuria, ${ }^{12,13}$ glycemic control might also help suppress the onset of CVD in patients with albuminuria. Furthermore, as the core target of multifactorial intensive therapy for T2DM, improved glycemic control is an important factor for improving kidney outcomes and achieving albuminuria remission. ${ }^{7,8}$

The recently developed SGLT2 inhibitors are now clinically available in several countries including Japan. The SGLTs, or sodium glucose co-transporters, encompass six isoforms: SGLT1-6. Among these, SGLT1 and SGLT2 are expressed in the proximal tubules of the kidney, and SGLT2 is responsible for approximately $90 \%$ of glucose reabsorption from the glomerular filtrate. ${ }^{14}$ Nearly all filtered glucose in the kidney is reabsorbed up until the point that the transporters reach their maximum glucose capacity. The plasma concentration at which this occurs is referred to as the renal threshold for glucose (RTG). Above this threshold, urinary glucose excretion increases in proportion to the 


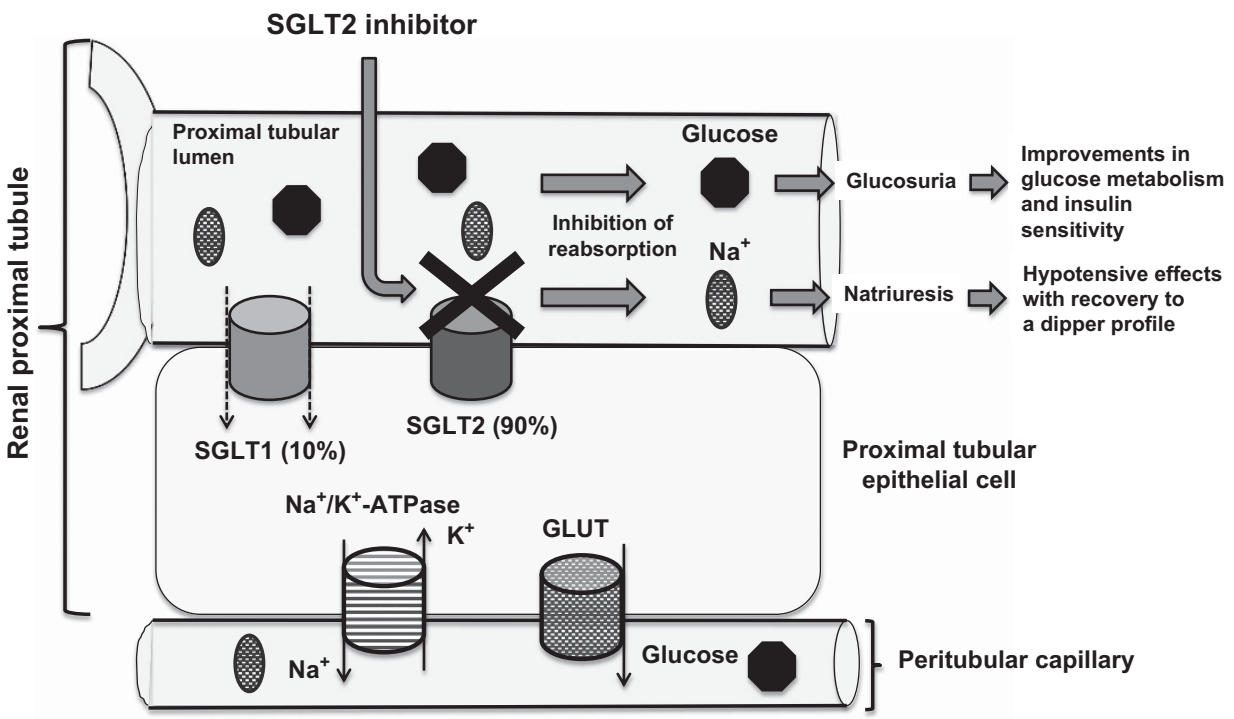

Figure 1 A schematic representation of a potential mechanism for SGLT2 inhibitor-mediated improvements in circadian BP rhythm.

plasma glucose concentration. SGLT2 inhibitors ameliorate hyperglycemia by lowering the RTG, which results in increased reabsorption of glucose in the renal proximal tubules and increased urinary excretion of glucose, also referred to as glycosuria. Empagliflozin is an oral SGLT2 inhibitor developed for the treatment of patients with T2DM that increases glycosuria and osmotic diuresis by lowering the RTG, thereby reducing plasma glucose concentrations in patients with hyperglycemia. Increased urinary glucose excretion also results in weight reduction due to caloric loss as well as a reduction in BP that is likely to be a secondary effect of osmotic diuresis. ${ }^{15}$

Appropriate BP management is an important component of a therapeutic regimen for patients with T2DM. Out-ofoffice BP measurements, such as home $\mathrm{BP}$ and ambulatory BP measurements, are recommended for estimating circadian $\mathrm{BP}$ rhythm. Appropriate management of circadian BP rhythm is an important factor for preventing renal deterioration and cardiovascular complications in patients with $\mathrm{T} 2 \mathrm{DM},{ }^{16}$ as increases in nocturnal $\mathrm{BP}$ and exaggerated BP variability in home BP and ambulatory BP measurements are associated with albuminuria progression and the occurrence of CVD in these patients. ${ }^{17-21}$ Antihypertensive therapies that not only decrease BP measurements in the clinical setting but also improve nocturnal hypertension and/or exaggerated BP variability are attractive candidates for a sophisticated therapeutic strategy.

Recently, the results of the EMPA-REG OUTCOME study demonstrated that add-on treatment with empagliflozin significantly reduced the occurrence of the primary composite cardiovascular outcome and death in patients with T2DM. ${ }^{22}$ Although the cardioprotective effects of empagliflozin were associated with BP reduction in the EMPAREG OUTCOME study, the potential effects of empagliflozin on circadian BP rhythm have not been investigated. Interestingly, a study by Takeshige et al. ${ }^{23}$ in this issue identified a direct correlation between the therapeutic effects of empagliflozin and alterations in circadian BP rhythm in salt-loaded obese Otsuka Long Evans Tokushima Fatty (OLETF) rats, a rat model of T2DM. The authors reported that empagliflozin significantly increased urinary glucose excretion and improved glucose metabolism and insulin resistance in obese OLETF rats. ${ }^{23}$ They further demonstrated that empagliflozin ameliorated salt-loading-mediated BP elevation and normalized aberrant diurnal BP variations to a dipper profile, and these effects were associated with an increase in urinary sodium excretion and an increased incidence of albuminuria reduction. ${ }^{23}$ The results of these well-performed experiments are interesting and also are important for understanding the pathophysiology of altered circadian BP rhythm and the potential therapeutic impact of SGLT2 inhibitors on the pathogenesis of T2DM. Furthermore, these findings provide a plausible mechanistic link between SGLT2 inhibitors and their potential protective effects on organs. Therefore, SGLT2 inhibitors might represent a promising therapeutic strategy for effectively treating both T2DM and diabetic nephropathy, and further experimental and clinical evidence is expected to address this hypothesis (Figure 1).

\section{CONFLICT OF INTEREST}

The authors declare no conflict of interest.

\section{ACKNOWLEDGEMENTS}

KT has received research grants from Daiichi Sankyo, Kyowa-hakko Kirin, Mochida, Chugai, Takeda, Novartis, MSD, Pfizer, AstraZeneca, Ono Pharmaceutical and Dainippon-Sumitomo, and honoraria from Mochida, Dainippon-Sumitomo, Nippon Boehringer Ingelheim, Kyowa-hakko Kirin, Daiichi Sankyo, Astellas, Chugai, Otsuka Pharmaceutical, Pfizer, Shionogi, Takeda and Sanofi. SU has received research grants from Shionogi, Astellas, Nippon Boehringer Ingelheim, MSD, Pfizer, Daiichi Sankyo, Novartis, AstraZeneca, Dainippon-Sumitomo and Kyowa-hakko Kirin, and honoraria from Daiichi Sankyo, Takeda, MSD, Shionogi, Boehringer Ingelheim and Kyowa-hakko Kirin.

1 Teramukai S, Okuda Y, Miyazaki S, Kawamori R, Shirayama M, Teramoto T. Dynamic prediction model and risk assessment chart for cardiovascular disease based on on-treatment blood pressure and baseline risk factors. Hypertens Res 2016; 39: 113-118.

2 Adler AI, Stevens RJ, Manley SE, Bilous RW, Cull CA, Holman RR. Development and progression of nephropathy in type 2 diabetes: the United Kingdom Prospective Diabetes Study (UKPDS 64). Kidney Int 2003; 63: 225-232.

3 Ninomiya $T$, Perkovic $V$, de Galan BE, Zoungas $S$, Pillai A, Jardine M, Patel A, Cass A, Neal B, Poulter N, Mogensen CE, Cooper M, Marre M, Williams B, Hamet P, Mancia G, Woodward M, Macmahon S, Chalmers J. Albuminuria and kidney function independently predict cardiovascular and renal outcomes in diabetes. J Am Soc Nephrol 2009; 20: 1813-1821.

4 Drury PL, Ting R, Zannino D, Ehnholm C, Flack J, Whiting M, Fassett R, Ansquer JC, Dixon P, Davis TM, Pardy C, Colman P, Keech A. Estimated glomerular 
filtration rate and albuminuria are independent predictors of cardiovascular events and death in type 2 diabetes mellitus: the Fenofibrate Intervention and Event Lowering in Diabetes (FIELD) study. Diabetologia 2011; 54: 32-43.

5 Wada T, Haneda M, Furuichi K, Babazono T, Yokoyama H, Iseki K, Araki S, Ninomiya T, Hara S, Suzuki $Y$, Iwano M, Kusano E, Moriya T, Satoh H, Nakamura H, Shimizu M, Toyama T, Hara A, Makino H. Clinical impact of albuminuria and glomerular filtration rate on renal and cardiovascular events, and all-cause mortality in Japanese patients with type 2 diabetes. Clin Exp Nephrol 2014; 18: 613-620.

6 Holtkamp FA, de Zeeuw D, de Graeff PA, Laverman GD, Berl T, Remuzzi G, Packham D, Lewis JB, Parving $\mathrm{HH}$, Lambers Heerspink HJ. Albuminuria and blood pressure, independent targets for cardioprotective therapy in patients with diabetes and nephropathy: a post hoc analysis of the combined RENAAL and IDNT trials. Eur Heart J 2011; 32: 1493-1499.

7 Kimura K, Okada H, Tamura K, Nishi S, Wada T, Fukui T. Committee of Evidence-based Practice Guideline for the Treatment of CKD 2013 Evidencebased clinical practice guideline for CKD 2013. Clin Exp Nephrol 2014; 18: 339-423.

8 Perkovic V, Heerspink HL, Chalmers J, Woodward M, Jun M, Li Q, MacMahon S, Cooper ME, Hamet $P$, Marre M, Mogensen CE, Poulter N, Mancia G, Cass A Patel A, Zoungas S. Intensive glucose control improves kidney outcomes in patients with type 2 diabetes. Kidney Int 2013; 83: 517-523.

9 Boussageon R, Bejan-Angoulvant T, Saadatian-Elahi M, Lafont S, Bergeonneau C, Kassai B, Erpeldinger S, Wright JM, Gueyffier F, Cornu C. Effect of intensive glucose lowering treatment on all cause mortality, cardiovascular death, and microvascular events in type 2 diabetes: meta-analysis of randomised controlled trials. BMJ 2011; 343: d4169.

10 Inzucchi SE, Bergenstal RM, Buse JB, Diamant M, Ferrannini E, Nauck M, Peters AL, Tsapas A, Wender R,
Matthews DR. Management of hyperglycemia in type 2 diabetes: a patient-centered approach: position statement of the American Diabetes Association (ADA) and the European Association for the Study of Diabetes (EASD). Diabetes Care 2012; 35: 1364-1379.

11 Gaede P, Lund-Andersen H, Parving HH, Pedersen $\mathrm{O}$. Effect of a multifactorial intervention on mortality in type 2 diabetes. N Engl J Med 2008; 358: 580-591.

12 Bakris GL, Agarwal R, Chan JC, Cooper ME, Gansevoort RT, Haller H, Remuzzi G, Rossing P, Schmieder RE, Nowack C, Kolkhof P, Joseph A, Pieper A, Kimmeskamp-Kirschbaum N, Ruilope LM. Effect of finerenone on albuminuria in patients with diabetic nephropathy: a randomized clinical trial. JAMA 2015; 314: 884-894.

13 Sato A. The necessity and effectiveness of mineralocorticoid receptor antagonist in the treatment of diabetic nephropathy. Hypertens Res 2015; 38: 367-374.

14 Nair S, Wilding JP. Sodium glucose cotransporter 2 inhibitors as a new treatment for diabetes mellitus. J Clin Endocrinol Metab 2010; 95: 34-42.

15 Tikkanen I, Narko K, Zeller C, Green A, Salsali A, BroedI UC, Woerle HJ. Empagliflozin reduces blood pressure in patients with type 2 diabetes and hypertension. Diabetes Care 2015; 38: 420-428.

16 Shimamoto K, Ando K, Fujita T, Hasebe N, Higaki J, Horiuchi $\mathrm{M}$, Imai $\mathrm{Y}$, Imaizumi $\mathrm{T}$, Ishimitsu $\mathrm{T}$, Ito $\mathrm{M}$, Ito $\mathrm{S}$, Itoh $\mathrm{H}$, Iwao $\mathrm{H}$, Kai $\mathrm{H}$, Kario $\mathrm{K}$, Kashihara $\mathrm{N}$, Kawano Y, Kim-Mitsuyama S, Kimura G, Kohara K, Komuro I, Kumagai $H$, Matsuura $H$, Miura K, Morishita R, Naruse M, Node K, Ohya Y, Rakugi H, Saito I, Saitoh S, Shimada K, Shimosawa T, Suzuki H, Tamura K, Tanahashi N, Tsuchihashi T, Uchiyama M, Ueda S, Umemura S. The Japanese Society of Hypertension Guidelines for the Management of Hypertension (JSH 2014). Hypertens Res 2014; 37: 253-387.

17 Astrup AS, Nielsen FS, Rossing P, Ali S, Kastrup J, Smidt UM, Parving $\mathrm{HH}$. Predictors of mortality in patients with type 2 diabetes with or without diabetic nephropathy: a follow-up study. J Hypertens 2007; 25: 2479-2485.

18 Tamura K, Yamauchi J, Tsurumi-Ikeya Y, Sakai M, Ozawa M, Shigenaga A, Azuma K, Okano Y, Ishigami T, Toya Y, Yabana M, Tokita Y, Ohnishi T, Umemura S. Ambulatory blood pressure and heart rate in hypertensives with renal failure: comparison between diabetic nephropathy and non-diabetic glomerulopathy. Clin Exp Hypertens 2008; 30: 33-43.

19 Eguchi K, Ishikawa J, Hoshide S, Pickering TG, Schwartz JE, Shimada K, Kario K. Night time blood pressure variability is a strong predictor for cardiovascular events in patients with type 2 diabetes. Am J Hypertens 2009; 22: 46-51.

20 Ozawa M, Tamura K, Okano Y, Matsushita K, Yanagi M, Tsurumi-Ikeya Y, Oshikawa J, Hashimoto T, Masuda S, Wakui H, Shigenaga A, Azuma K, Ishigami T, Toya Y, Ishikawa T, Umemura S. Identification of an increased short-term blood pressure variability on ambulatory blood pressure monitoring as a coronary risk factor in diabetic hypertensives. Clin Exp Hypertens 2009; 31: 259-270.

21 Oh SW, Han SY, Han KH, Cha RH, Kim S, Yoon SA, Rhu DR, Oh J, Lee EY, Kim DK, Kim YS. Morning hypertension and night non-dipping in patients with diabetes and chronic kidney disease. Hypertens Res 2015; 38: 889-894.

22 Zinman B, Wanner C, Lachin JM, Fitchett D, Bluhmki E, Hantel S, Mattheus M, Devins T, Johansen OE, Woerle HJ, Broedl UC, Inzucchi SE. Empagliflozin, cardiovascular outcomes, and mortality in Type 2 Diabetes. N Engl J Med 2015; 373: 2117-2128.

23 Takeshige Y, Fujisawa Y, Rahman A, Kittikulsuth W, Nakano D, Mori H, Masaki T, Ohmori K, Kohno M, Ogata $H$, Nishiyama A. A sodium-glucose co-transporter 2 inhibitor empagliflozin prevents abnormality of circadian rhythm of blood pressure in salt-treated obese rats. Hypertens Res 2016; 39: 415-422. 